\title{
Foraging experiences affect the importance of chemical cues in patch- leaving decision of Neoseiulus womersleyi Schicha (Acari, Phytoseiidae)
}

\author{
Taro MAEDA*
}

Natural Enemies Laboratory, Insect Interaction Research Unit, Dicision of Insect Sciences, National Institute of Agrobiological Sciences, Tsukuba, Ibaraki 305-0851, Japan

(Received 30 September 2010; Accepted 21 December 2010)

\begin{abstract}
To investigate whether the informational value of herbivore-induced plant volatiles (HIPV) changes according to foraging conditions, eight populations of the predatory mite Neoseiulus womersleyi were reared under two conditions. The patch-leaving tendency was tested using kidney bean leaf disc in a wind tunnel as a mimic prey patch. When predators were reared under unstable rearing conditions, patch-leaving tendencies were increased by HIPV in the airflow. Patch-leaving tendencies of predators reared under stable rearing conditions were not affected by the HIPV. These results suggest that the informational value of HIPV in a predator's patchleaving decision would differ depending on foraging conditions.
\end{abstract}

Key words: herbivore-induced plant volatiles, informational value, olfactory response, patch-leaving decision, residence time, Tetranychus urticae

\section{INTRODUCTION}

The classical marginal value theorem states that a forager should leave a patch once its net energy gain per unit time equals the average rate of energy gain over all patches in the entire habitat (Charnov, 1976). Thus, in order for a predator to decide the optimal residence time in a prey patch, it must evaluate the resource level both inside and outside a current patch (Stephens and Krebs, 1986; Dicke and Vet, 1999). What clues does the predator use in this evaluation?

Many predators and parasitoids adjust their residence time in a prey/host patch according to multiple pieces of information. For example, the residence time of parasitoid wasps is affected by factors such as travel time, quality of current host patch, herbivore-induced plant volatiles (HIPV), and host distribution pattern (e.g., Van Baaren et al., 2005; Burger et al., 2006; Tentelier et al., 2006; Thiel et al., 2006; Tentelier and Fauvergue, 2007). Orb-web spiders relocate their webs based on their feeding experiences and current prey capture rate (Janetos, 1986). In its natural environment, the orb-web spider Cyclosa argenteoalba appears to enhance its foraging efficiency by using past foraging experience in the decision of web relocation (Nakata and Ushimaru, 1999;

* Corresponding author: e-mail: tarom@affrc.go.jp

DOI: $10.2300 /$ acari.20.9 
Nakata et al., 2003).

Theoretical studies have argued that the importance of experience in the evaluation of a foraging site depends on the rate at which the environment changes (McNamara and Houston, 1987). When the environment changes slowly and/or infrequently, the animal should use past information more often than it would when the environment changes rapidly and/or often. The residence times of predatory mites, such as Phytoseiulus persimilis and Neoseiulus womersleyi, are affected by the presence of HIPV from outside the patch and previous foraging experiences (Maeda et al., 1998; Mayland et al., 2000; Maeda and Takabayashi, 2001). P. persimilis and $N$. womersleyi are known as effective natural enemies of spider mites. Predatory mites appear to use both present information (HIPV from outside the patch) and past information (foraging experience) to respond to the resource level in a habitat (Maeda and Takabayashi, 2005). Of particular interest is how predators use present and past information in making patch-leaving decisions under various conditions. The objective of the current study is to investigate how the predatory mite $N$. womersleyi uses HIPV in patch-leaving decisions under conditions in which the rate of environment change varies. The effects of HIPV on the residence time of $N$. womersleyi were investigated after rearing the predatory mites under one of two rearing conditions.

The olfactory response of predatory mites in a Y-tube olfactometer is influenced by genetic factors (Margolies et al., 1997; Jia et al., 2002). For example, Maeda (2005) documented interpopulation variation in olfactory responses of $N$. womersleyi. Another intriguing question is whether the difference in the olfactory response influences the patch-leaving decision in the presence of HIPV. In the present study, we use eight local populations of N. womersleyi to investigate this question.

\section{MATERIALS AND METHODS}

\section{Plants}

Kidney bean plants (Phaseolus vulgaris 'Nagauzura') were used as a food source for two spotted spider mite, Tetranychus urticae Koch, and as odor sources for bioassays. The plants were grown in plastic pots filled with vermiculite in a climate-controlled room $\left(19 \pm 1{ }^{\circ} \mathrm{C}, 50-70 \%\right.$ relative humidity [RH], 16L:8D photoperiod at ca. $4000 \mathrm{~lx}$ ). When the two primary leaves had fully unfolded (about 2 to 3 weeks after germination), the plants were used in the experiments.

\section{Herbivorous mites}

Tetranychus urticae were obtained from a laboratory culture that had been maintained on kidney bean plants for more than 2 years under the following conditions: $25 \pm 3{ }^{\circ} \mathrm{C}, 60-80 \% \mathrm{RH}$, and 16L:8D photoperiod. About 70 kidney bean plants with 2 fully unfolded primary leaves were placed in the T. urticae culture every week.

\section{Rearing conditions for predatory mites}

The predatory mites $N$. womersleyi were collected from eight different sites in Japan (Table 1). The olfactory responses of these populations were tested in the Y-tube olfactometer (Maeda, 2005). Each population was named according to its collection site and host-plant species. All 
populations were maintained on an artificial arena (acrylic resin plates, $20 \times 30 \times 0.5 \mathrm{~cm}$; Maeda et al., 2000) under the following conditions: $25 \pm 1{ }^{\circ} \mathrm{C}, 60-80 \% \mathrm{RH}$, and $16 \mathrm{~L}: 8 \mathrm{D}$ photoperiod. Each plate had four rubber feet $(5 \mathrm{~cm}$ diameter, $4 \mathrm{~cm}$ height) and was placed in a plastic box (30 $\times 47 \times 12 \mathrm{~cm})$, having a lid with a rectangular aperture $(24 \times 34 \mathrm{~cm})$ covered with nylon gauze ( $0.2 \mathrm{~mm}$ mesh). Five bean leaves infested with $T$. urticae (30 to 50 adult females and other prey stages per leaf) were placed on each plate three times per week, and under these conditions, 40 to 60 adult female predatory mites were maintained per generation per population.

After rearing the predators on the artificial arena for more than 5 months, each population was divided into two subgroups and were reared on different rearing conditions from egg to adult (25 $\pm 1{ }^{\circ} \mathrm{C}, 60-80 \% \mathrm{RH}$, and 16L:8D). One subgroup was reared on the artificial arena (Maeda et al., 2000), and the other was reared on detached leaf cultures (Maeda et al., 2000), which consisted of a T. urticae-infested leaf placed on water-saturated cotton wool in a petri dish $(9 \mathrm{~cm}$ diameter). Five $N$. womersleyi females were introduced onto each leaf, which was heavily infested with $T$. urticae so that the offspring of the predatory mites grew to adulthood with sufficient prey. On the artificial arena, the infested leaves gradually dried out within 2 days, and the predatory mites had to move to newly provided leaves to obtain food (Maeda et al., 2000). The predators on the detached leaf culture, however, were always in a prey-abundant patch, and, as a result, conditions of the artificial arena were more variable than conditions of the detached leaf culture (Maeda et al., 2000).

\section{Patch-leaving tendencies}

The patch-leaving tendencies of the eight predator populations were tested using a kidney

Table 1. Collection sites, dates, host plants, and olfactory responses in a Y-tube olfactometer of eight local populations of Neoseiulus womersleyi

\begin{tabular}{|c|c|c|c|c|}
\hline Population name & Sampling site & Date & Host plant & Olfactory response $(\%)^{*}$ \\
\hline AZK & $\begin{array}{l}\text { Tsukuba, Ibaraki } \\
\left(36^{\circ} 05^{\prime} 02^{\prime \prime} \mathrm{N}, 140^{\circ} 06^{\prime} 46^{\prime \prime} \mathrm{E}\right)\end{array}$ & Sept 2002 & kudzu vine & 51.1 \\
\hline HMK & $\begin{array}{l}\text { Hamaoka, Shizuoka } \\
\left(34^{\circ} 37^{\prime} 03^{\prime \prime N}, 138^{\circ} 10^{\prime} 07^{\prime E}\right)\end{array}$ & Jun 2003 & kudzu vine & 62.7 \\
\hline KNT & $\begin{array}{l}\text { Kanaya, Shizuoka } \\
\left(34^{\circ} 48^{\prime} 20^{\prime \prime} \mathrm{N}, 138^{\circ} 08^{\prime} 10^{\prime \prime} \mathrm{E}\right)\end{array}$ & Jun 2003 & tea & 70.7 \\
\hline MKK & $\begin{array}{l}\text { Mikuni, Fukui } \\
\left(36^{\circ} 14^{\prime} 19^{\prime \prime N}, 136^{\circ} 08^{\prime} 29^{\prime \prime} E\right)\end{array}$ & Sept 2002 & kudzu vine & 61.7 \\
\hline OTK & $\begin{array}{l}\text { Otsu, Shiga } \\
\left(34^{\circ} 58^{\prime} 04^{\prime \prime N}, 135^{\circ} 57^{\prime} 30 " \mathrm{E}\right)\end{array}$ & Jun 2003 & kudzu vine & 59.8 \\
\hline TJY & $\begin{array}{l}\text { Tokashiki, Okinawa } \\
\left(26^{\circ} 09^{\prime} 57^{\prime \prime N}, 127^{\circ} 20^{\prime} 55^{\prime \prime E}\right)\end{array}$ & Oct 2003 & fatsia & 72.5 \\
\hline UJK & $\begin{array}{l}\text { Ujitawara, Kyoto } \\
\left(34^{\circ} 52^{\prime} 46^{\prime \prime N}, 135^{\circ} 51^{\prime} 46^{\prime \prime E}\right)\end{array}$ & Jun 2003 & kudzu vine & 65.3 \\
\hline YSK & $\begin{array}{l}\text { Yoshida, Shizuoka } \\
\left(34^{\circ} 45^{\prime} 11^{\prime \prime N}, 138^{\circ} 16^{\prime} 15^{\prime E} \mathrm{E}\right)\end{array}$ & Jun 2003 & kudzu vine & 56.8 \\
\hline
\end{tabular}

* Olfactory response: percent of individuals that prefer HIPV to intact plant volatiles in a Y-tube olfactometer. Source: data from Maeda (2005). 
bean leaf disc (30 $\mathrm{mm}$ diameter), which was used as a mimic prey patch, and a rectangular piece $(15 \times 30 \mathrm{~mm})$ of kidney bean leaf. Five adult $T$. urticae females were placed on each leaf disc and allowed to oviposit for $24 \mathrm{~h}$ under the following conditions: $25 \pm 2{ }^{\circ} \mathrm{C}, 50-70 \% \mathrm{RH}$, and 16L:8D photoperiod. The HIPV released from the leaf disc under these conditions did not affect $N$. womersleyi residence time (Maeda and Takabayashi, 2001). The mean number of T. urticae eggs laid on a leaf disc $(59.68 \pm 0.41)$ was significantly higher than the number of eggs consumed by $N$. womersleyi in a day (18.83 \pm 0.50 ; Maeda, 2005), and the rectangular piece of leaf was heavily infested with T. urticae so that the dispersed predatory mites remained on the leaf throughout the experimental period (Maeda and Takabayashi, 2001). The leaf disc and the rectangular piece of leaf were placed on water-saturated cotton wool in a plastic petri dish $(90 \mathrm{~mm}$ diameter, $14 \mathrm{~mm}$ height). A gravid female N. womersleyi, which had been reared on either the artificial arena or the detached leaf culture, was placed on the leaf disc, and after $30 \mathrm{~min}$ of acclimation, the leaf disc was connected to the leaf rectangle using a bridge made from Parafilm $(30 \times 3 \mathrm{~mm})$. The petri dishes were then placed in a wind tunnel $\left(70 \times 210 \times 65 \mathrm{~cm}, 25 \pm 2{ }^{\circ} \mathrm{C}, 50-70 \% \mathrm{RH}\right)$, and, to prevent the predators from detecting the HIPV released from the infested rectangular leaf, the petri dishes were placed such that the bridge had an angle of $45^{\circ}$ relative to the wind direction (Maeda and Takabayashi, 2001). The air entering the wind tunnel (wind speed $=10-15 \mathrm{~cm} \mathrm{~s}^{-1}$ ) was cleaned using a granular activated charcoal filter. To investigate the effect of HIPV on the patch-leaving tendency, either $20 \mathrm{~T}$. urticae-infested kidney bean plants or 20 intact bean plants were placed at the upwind end of the wind tunnel as odor sources. After $6 \mathrm{~h}$, the location of the predators was recorded $(n=20-44)$. The patch-leaving tendency was defined as the percent of individuals that left the leaf disc during the experimental period.

\section{Statistical analyses}

Likelihood ratio tests were conducted followed by logistic regression analysis to test the influence of the population, the odor source in the wind tunnel, and the rearing conditions on $N$. womersleyi patch-leaving tendencies. All analyses were performed in JMP 5.12 software (SAS, 2002; Sall et al., 2004).

The relationship between olfactory responses in a Y-tube olfactometer (Maeda, 2005) and the effects of HIPV on patch-leaving tendencies was tested by simple regression analysis. In this analysis, the data from Maeda (2005), where olfactory response was defined as the percent of individuals that prefer HIPV to intact plant volatiles, were used after arcsine-root transformation. The predators used by Maeda (2005) were tested after being reared on the artificial arena. In the current study, the effect of HIPV on the patch-leaving tendency was defined as the difference in patch-leaving tendencies between the intact plant volatiles and the HIPV; the difference was arcsine-root transformed before statistical analysis.

\section{RESULTS}

The likelihood ratio test followed by logistic regression analysis showed that the patch-leaving tendencies significantly differed among populations $(P<0.0001$; Table 2$)$. The rearing condition itself had a significant effect on the patch-leaving tendency $(P<0.0001$; Table 2$)$ with the 
tendencies for the detached leaf culture subgroup being higher than the subgroup reared on the artificial arena, regardless of whether HIPV were present (Fig. 1, 2).

The interaction between the population and the rearing condition, and between the odor source and the rearing condition also had significant effects on the tendency to leave $(P=0.013$ and 0.0194 , respectively; Table 2). To test the effect of odor source under each rearing condition, the results from each rearing condition were analyzed separately with the likelihood ratio test (Tables $3,4)$. When the predatory mites were reared on the artificial arena, the leaving tendencies were significantly different among the populations $(P<0.0001)$ and were higher in the presence of HIPV $(P=0.0064$, Table 3$)$. Six of eight populations showed a higher patch-leaving tendency in

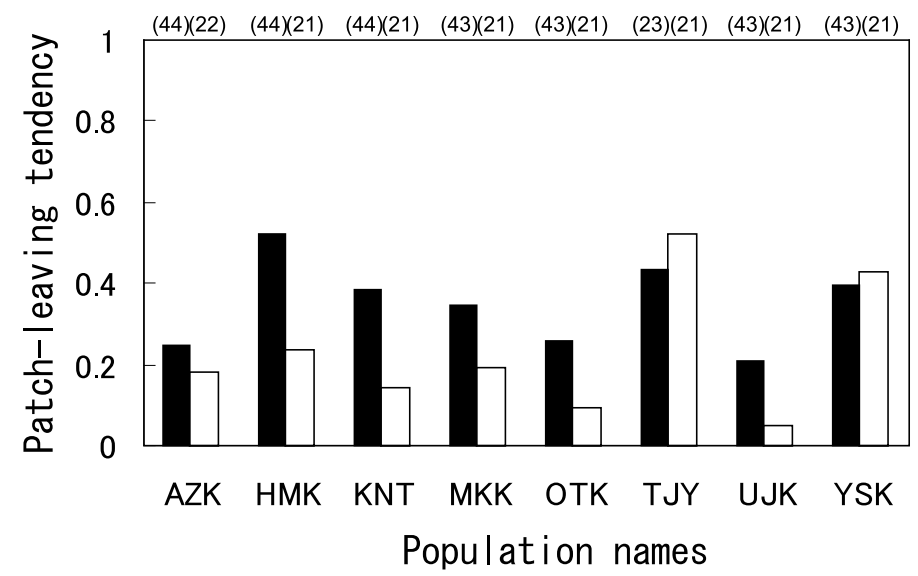

Fig. 1. Patch-leaving tendencies of eight Neoseiulus womersleyi populations that had been reared on an artificial arena, in the presence (black bars) and absence (white bars) of HIPV. The numbers at the top of the graph indicate the number of the tested individuals.

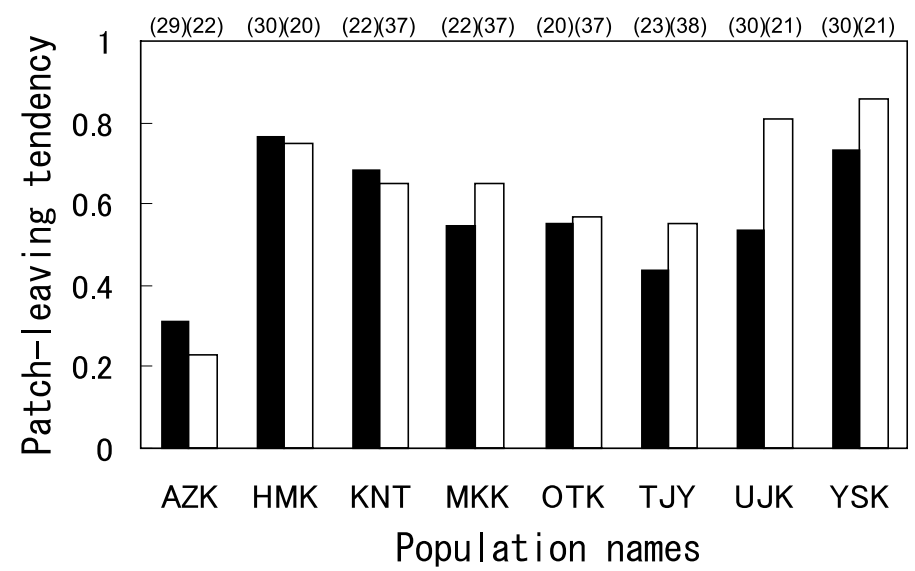

Fig. 2. Patch-leaving tendencies of eight Neoseiulus womersleyi populations that had been reared on a detached leaf culture, in the presence (black bars) and absence (white bars) of HIPV. The numbers at the top of the graph indicate the number of the tested individuals. 
the presence of HIPV (Fig. 1). When the predators were reared on the detached leaf culture, on the other hand, the patch-leaving tendency was not affected by the odor source (Fig. 2, Table 4).

A simple regression analysis showed no significant relationship between the olfactory response in the Y-tube olfactometer and the effect of HIPV in the wind tunnel on the patch-leaving tendencies of the predators that had been reared on the artificial arena $(F=0.0378, n=8, P=$ 0.8523; Fig. 3). The HIPV did not have a significant effect on the patch-leaving tendency of predators reared on the detached leaf culture, and no further regression analysis was performed.

\section{DISCUSSION}

When the predators were reared under stable rearing conditions (the detached leaf culture in this study), the patch-leaving tendency was not affected by HIPV in the airflow. On the other hand, when the predatory mites were reared under unstable rearing conditions (artificial arena), however, the patch-leaving tendency was significantly affected by the presence of HIPV. This difference was not caused by genetic difference because the predatory mites had been reared on the artificial arena only for 1 generation. The results of the present study are similar to those of

Table 2. Logistic regression analysis of the effect of population, odor source, and rearing conditions on the patch-leaving tendency of Neoseiulus womersleyi (likelihood ratio test)

\begin{tabular}{lccc}
\hline \multicolumn{1}{c}{ Source } & $d f$ & $X^{2}$ & $P$ \\
\hline Population & 7 & 42.806 & $<\mathbf{0 . 0 0 0 1}$ \\
Odor source & 1 & 3.213 & 0.0731 \\
Rearing condition & 1 & 73.030 & $<\mathbf{0 . 0 0 0 1}$ \\
Population $\times$ odor source & 7 & 8.382 & 0.3001 \\
Population $\times$ rearing condition & 7 & 23.658 & $\mathbf{0 . 0 0 1 3}$ \\
Odor source $\times$ rearing condition & 1 & 5.462 & $\mathbf{0 . 0 1 9 4}$ \\
Population $\times$ odor source $\times$ rearing condition & 7 & 5.072 & 0.6512 \\
\hline
\end{tabular}

Table 3. Logistic regression analysis of the effect of population and odor source on the patch-leaving tendency of Neoseiulus womersleyi that had been reared on the artificial arena (likelihood ratio test)

\begin{tabular}{lccc}
\hline \multicolumn{1}{c}{ Source } & $d f$ & $X^{2}$ & $P$ \\
\hline Population & 7 & 30.465 & $<\mathbf{0 . 0 0 0 1}$ \\
Odor source & 1 & 7.434 & $\mathbf{0 . 0 0 6 4}$ \\
Population $\times$ odor source & 7 & 9.168 & 0.2408 \\
\hline
\end{tabular}

Table 4. Logistic regression analysis of the effect of population and odor source on the patch-leaving tendency of Neoseiulus womersleyi that had been reared on the detached leaf culture (likelihood ratio test)

\begin{tabular}{lccc}
\hline \multicolumn{1}{c}{ Source } & $d f$ & $X^{2}$ & $P$ \\
\hline Population & 7 & 35.331 & $<\mathbf{0 . 0 0 0 1}$ \\
Odor source & 1 & 0.177 & 0.6740 \\
Population $\times$ odor source & 7 & 4.308 & 0.7437 \\
\hline
\end{tabular}




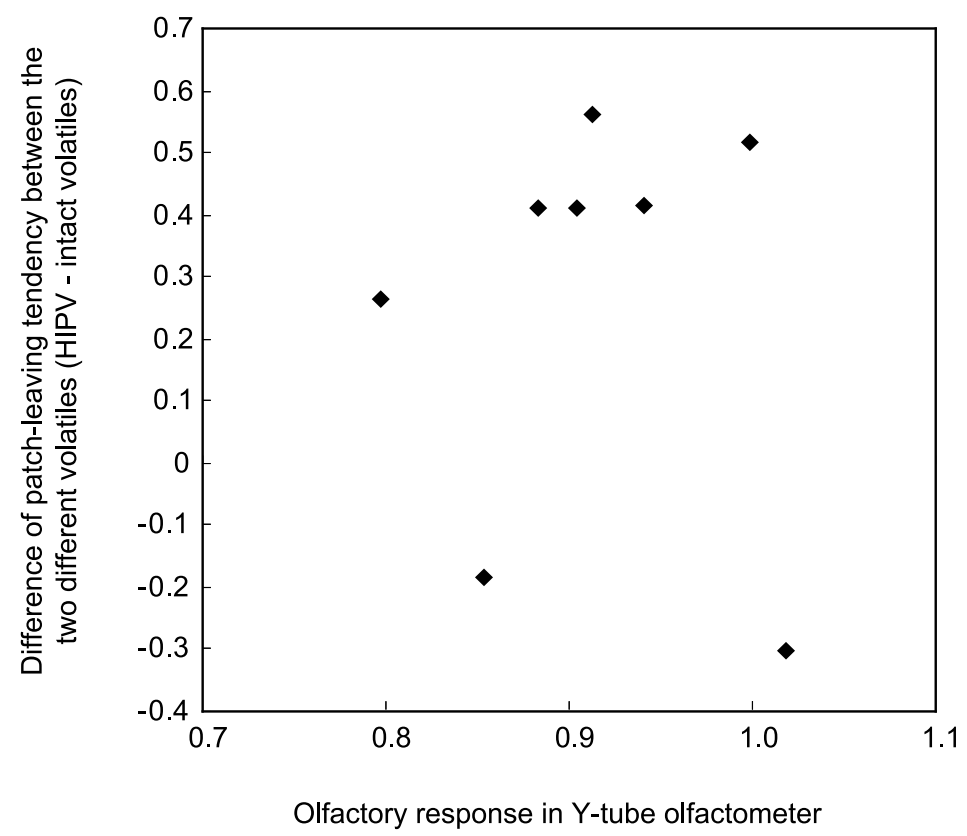

Fig. 3. Relationship between the olfactory responses in a Y-tube olfactometer (Maeda 2005) and the effects of HIPV on the patch-leaving tendency. The olfactory response was defined as the percent of individuals that prefer HIPV to intact plant volatiles (Maeda 2005). The effect of HIPV on the patch-leaving tendencies was defined as the difference in patch-leaving tendencies between in HIPV-airflow and control-airflow: the tendency in the HIPV minus that in the intact plant volatiles. Both parameters were arcsine-root transformed. The dots represent data for eight local populations that had been reared on the artificial arena.

an earlier theoretical study (McNamara and Houston, 1987). When foraging conditions change frequently, experience may not play an important role in determining present and future foraging potential; however, the presence of HIPV from outside the currently inhabited prey patch provides information to the predators about nearby prey patches. Therefore, predators that have experienced unstable rearing conditions would use the information provided by HIPV in their patch-leaving decision. Under stable rearing conditions, the environment changes slowly and/ or infrequently, and predators would know their surrounding conditions based on experience. Because the accuracy of volatile information is affected by wind speed and direction, when past information is reliable, the relative importance of HIPV may be low, resulting in the patchleaving tendency of the predatory mites not being affected by HIPV.

A possible proximate mechanism for the lack of effects of HIPV on the patch-leaving tendency of $N$. womersleyi when the predators had been reared on the detached leaf culture is nonattractiveness of HIPV. The olfactory response of $N$. womersleyi has reported to be affected by rearing conditions (Maeda et al., 2000). When N. womersleyi is reared in the artificial arena, it shows a significant preference for HIPV in a Y-tube olfactometer, but when reared on the detached leaf culture, no preference for HIPV is shown and HIPV is not a factor in their patch- 
leaving decision.

Maeda and Takabayashi (2005) discussed that when the predatory mites have experienced starvation, the predatory mites would estimate the quality of the environment to be lower or more variable; i.e., no new prey-patches might be available after they leave the current patch and the predators are less inclined to leave a current patch with prey than predators that have always had prey close-by. In the current study, when a forager has experienced stable and prey-abundant foraging conditions (the detached leaf culture in this study), the rate of average energy gain in that habitat is estimated as high, and thus the residence time in a poor-prey patch is expected to be short. On the other hand, under variable or unstable rearing conditions when the average gain rate is estimated as low, predators should stay longer in the poor-prey patch. The present study supports the expectation of the optimal foraging theory. The patch-leaving tendencies of the predators that had been reared on the artificial arena were lower than those reared on the detached leaf culture, irrespective of the presence of HIPV.

The absence of any correlation between the effects of HIPV on the patch-leaving tendency and the preference for HIPV in a Y-tube olfactometer suggests that the olfactory response in the Y-tube olfactometer did not always represent the ability to receive and to use the HIPV information. For example, the patch-leaving tendency of the TJY population, which showed the highest preference for HIPV in the Y-tube olfactometer (Table 1; Maeda, 2005), showed no difference in response to HIPV even when reared on the artificial arena. On the other hand, AZK and OTK populations use HIPV to decide the residence time, but they show no preference to HIPV in the Y-tube olfactometer. This suggests that the patch-leaving decision of N. womersleyi is controlled by factors other than the attraction to HIPV. As reported previously, predators would use HIPV in both prey-finding and patch-leaving activities (Maeda et al., 1998; Mayland et al., 2000; Maeda and Takabayashi, 2001), but the way HIPV is used in foraging activities may differ among local populations; some predators use HIPV information only in patch-leaving decisions, whereas other predators use HIPV only when searching for a new prey patch. This study revealed the different ways that HIPV is used in prey-finding and patch-leaving activities.

\section{ACKOWLDGEMENTS}

I thank Dr. N. Hinomoto for critical reviews of an earlier draft. This work was supported in part by Grants for Young Scientist (B) (No. 19780045) from the Ministry of Education, Culture, Sports and Technology, Japan.

\section{REFERENCES}

ABurger, J. M., Y. Huang, L. Hemerik, J. C. Lenteren and L. E. M. Vet (2006) Flexible use of patch-leaving mechanisms in a parasitoid wasp. Journal of Insect Behavior, 19: 155-170.

Charnov, E. L. (1976) Optimal foraging: the marginal value theory. Theoretical Population Biology, 9: 129-136.

Dicke, M. and L. E. M. Vet (1999) Plant-carnivore interactions: evolutionary and ecological consequences for plant, herbivore and carnivore. In: Herbivores: Between Plants and Predators (eds., Oliff, H., V. K. Brown and R. H. Drent), pp. 483-520, Blackwell Science, Oxford.

Janetos, A. C. (1986) Web-site selection: Are we asking the right questions? In: Spiders: Webs, Behavior and Evolution (ed., 
Shear, W. A.), pp. 9-22, Stanford University Press, Stanford.

Jia, F., D. C. Margolies, J. E. Boyer and R. E. Charlton (2002) Genetic variation in foraging traits among inbred lines of a predatory mite. Heredity, 89: 371-379.

Maeda, T. (2005) Correlation between olfactory responses, dispersal tendencies, and life-history traits of the predatory mite Neoseiulus womersleyi (Acari: Phytoseiidae) of eight local populations. Experimental and Applied Acarology, 37: 6782.

Maeda, T. and J. Takabayashi (2001) Patch leaving decision of the predatory mite Amblyseius womersleyi (Acari: Phytoseiidae) based on multiple information from both inside and outside a prey patch. Journal of Insect Behavior, 14: 829-839.

Maeda, T. and J. Takabayashi (2005) Effects of foraging experiences on residence time of the predatory mite Neoseiulus womersleyi in a prey patch. Journal of Insect Behavior, 18: 323-334.

Maeda, T., J. Takabayashi, S. Yano and A. Takafuji (1998) Factors affecting the resident time of the predatory mite Phytoseiulus persimilis (Acari: Phytoseiidae) in a prey patch. Applied Entomology and Zoology, 33: 573-576.

Maeda, T., J. Takabayashi, S. Yano and A. Takafuji (2000) The effects of rearing conditions on the olfactory response of predatory mites, Phytoseiulus persimilis and Amblyseius womersleyi (Acari: Phytoseiidae). Applied Entomology and Zoology, 35: 345-351.

Margolies, D. C., M. W. Sabelis and J. E. J. Boyer (1997) Response of a phytoseiid predator to herbivore-induced plant volatiles: selection on attraction and effect on prey exploitation. Journal of Insect Behavior, 10: 695-709.

Mayland, H., D. C. Margolies and R. E. Charlton (2000) Local and distant prey-related cues influence when an acarine predator leaves a prey patch. Entomologia Experimentalis et Applicata, 96: 245-252.

McNamara, J. M. and A. I. Houston (1987) Memory and the efficient use of information. Journal of Theoretical Biology, 125: 385-395.

Nakata, K. and A. Ushimaru (1999) Feeding experience affects web relocation and investment in web threads in an orbweb spider, Cyclosa argenteoalba. Animal Behavior, 57: 1251-1255.

Nakata, K., A. Ushimaru and T. Watanabe (2003) Using Past Experience in Web Relocation Decisions Enhances the Foraging Efficiency of the Spider Cyclosa argenteoalba. Journal of Insect Behavior, 16: 371-380.

Sall, J., L. Creighton and A. Lehman (2005) JMP Start Statistics, 3rd edn. 541p., SAS Institute, Cary.

SAS (2002) JMP User's Guide, version 5. 304 p., SAS Institute, Cary.

Stephens, D. W. and J. R. Krebs (1986) Foraging Theory. 262 p., Princeton Univ. Press, Princeton.

Tentelier, C., E. Desouhant and X. Fauvergue (2006) Habitat assessment by parasitoids: mechanisms for patch use behavior. Behavioral Ecology, 17: 515-521.

Tentelier, C. and X. Fauvergue (2007) Herbivore-induced plant volatiles as cues for habitat assessment by a foraging parasitoid. Journal of Animal Ecology, 76: 1-8.

Thiel. A., G. Driessen and T. S. Hoffmeister (2006) Different habitats, different habits? Response to foraging information in the parasitic wasp Venturia canescens. Behavioral Ecology and Sociobiology, 59: 614-623.

Van Baaren, J., G. Boivin and Y. Outreman (2005) Patch exploitation strategy by an egg parasitoid in constant or variable environment. Ecological Entomology, 30: 502-509.

\section{摘要}

ケナガカブリダニのパッチ移出時期決定における植物由来揮発性化学物質の重要性に採 餌経験が及ぼす影響

前田 太郎（農業生物資源研究所）

採餌環境によって植物由来揮発性物質の情報的価值が変化するかどうか調べるため，ケナ ガカブリダニ 8 個体群を異なる条件で飼育した後，インゲン葉リーフディスク (パッチ) か らの移出時期を風洞内で観察した. 不安定な条件で飼育したカブリダニのパッチ移出時期は, 風上からの植物由来揮発性物質によって早まったのに対し，安定した条件で飼育したカブリ 
ダニの移出時期は揮発性物質の影響を受けなかった。 これらの結果は, 植物由来揮発性物質 の情報的価值が，採餌環境によって変化することを示唆している. 